\title{
BYTTNERIA CARIPENSIS (STERCULIACEAE) UNA NUEVA ESPECIE DE VENEZUELA
} por CARMEN L. CRISTOBAL y MARIA M. ARBO*

\section{Summary}

Byttneria caripensis Cristóbal (section Crassipetala) from Edo. Bolívar, Venezuela is described as new. The anatomy of the leaf nectaries and the minor venation are also studied. The very peculiar size and shape of the glandular cavities of the multiaperturate nectaries are stressed. Two illustrations are provided.

\section{Byttneria caripensis Cristóbal nov. sp. \\ Fig. 1-2}

Frutex scandens?, ramis ad apicem pilis brevibus stellaribus simplicibus et glandularibus tectis, aculeis recurvatis parvis instructis. Petioli $5-14 \mathrm{~mm}$ longi, aculeati. Laminae $4-5 \mathrm{~cm}$ iongae, $1.3-2 \mathrm{~cm}$ latae, ovato-lanceolatae, serrulatae usque ad subintegrae, pilis brevibus siellaribus sparsis, subtus aliquanto abundantibus; nectario muitiaperturato reticulato inferne base venae mediae patente disposito. In florescentiae axillares. Peiala crassa purpurea unguiculata, lamina cylindrica acuta, aliquis pilis glandularibus. Tubus staminalis crassus; staminodia 3 mamillis latere externo instructis. Fructus ignotus.

Typus speciei: VENEZUELA, Bolívar, Laguna de Caripo, al río Orinoco cerca de la boca del R. Suapure. N.V. espina, 9. Oct. 1964. Ojasti 14. (VEN).

* Instituto de Botánica del Nordeste. Casilla de Correo 209, 3400 Corrientes, Argentina. Miembros de la Carrera del Investigador Científico y Tecnológico, CONICET. 
Arbusto escandente ?, tallos de las ramas floríferas muy delgados, cerca $0.7 \mathrm{~mm}$ diám. en el extremo, pubescentes, pelos estrellados diminutos, simples y glandulares rojizos entremezclados, además aguijones dispersos, recurvados, 0.5-1.5 mm long., con la base pubescente y estriada y el ápice agudo, lustroso y glabro. Estípulas fugaces, no vistas. Pecíolo 5-14 mm long. por $0.5 \mathrm{~mm}$ diám., terete, pelos algo más largos y rígidos que los del tallo y uno o más aguijones en la cara externa. Lámina membranácea ovallanceolada, base redondeada o subcuneada, margen serrulado hasta subentero; $4-7.5 \mathrm{~cm}$ long. por $1.3-2 \mathrm{~cm}$ lat., pelos estrellados cortos y rígidos uniformemente distribuidos en ambas caras, de más ramas y más abundantes en el hipofilo de manera que los extremos se entrecruzan, dispersos en el epifilo; venación sobresaliente en el hipofilo, 2 pares de venas secundarias basales y $3-5$ en los dos tercios apicales de la lámina; nectario 1, ovalado, $2 \mathrm{~mm}$ long. por 1 mm lat., ubicado en la base de la vena media sobre el hipofilo, castaño claro, lustroso, glabro, más ancho que la vena y sobresaliente, margen liso el resto de la superficie levemente cóncava, multiaperturado, aberturas grandes, muy notables, sinuosas formando un retículo irregular.

Flores en cimas axilares muy acortadas, pedúnculos y pedicelos 2-3 mm long., pubescentes, brácteas triangulares. Sépalos 5, aovados, agudos, connados en la base, cara externa cubierta de pelos estrellados, cara interna purpúrea, con pelos glandulares capitados dispersos, diminutos, rojizos, $4 \mathrm{~mm}$ long. por $2 \mathrm{~mm}$ lat. Pétalos 5, carnosos, purpúreos, unguiculados, uña $1.5 \mathrm{~mm}$ long., adosada al borde del tubo estaminal, base de la uña breve más corta que la capucha, acintada; capucha con un pliegue profundo en la línea media donde es levemente pubescente, alas redondeadas, glabras; lámina del pétalo $3.5 \mathrm{~mm}$ long., erguida, base algo aplanada progre-

Fig. 1. Byttneria caripensis. A, rama. B, pétalo: cara interna. C, tubo estaminal. D, idem: cara superior. E, ídem: cara interna. Tipo. 


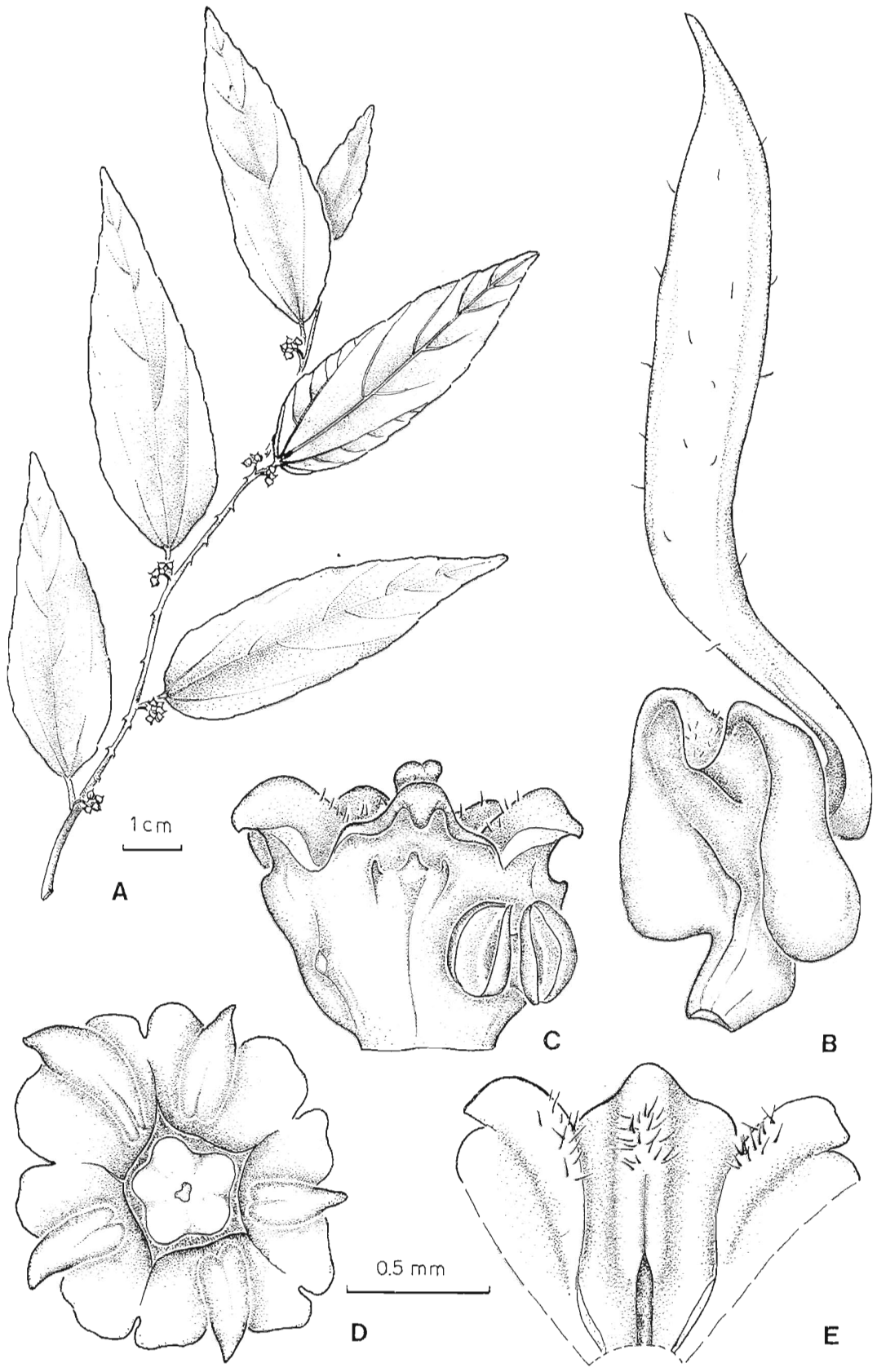



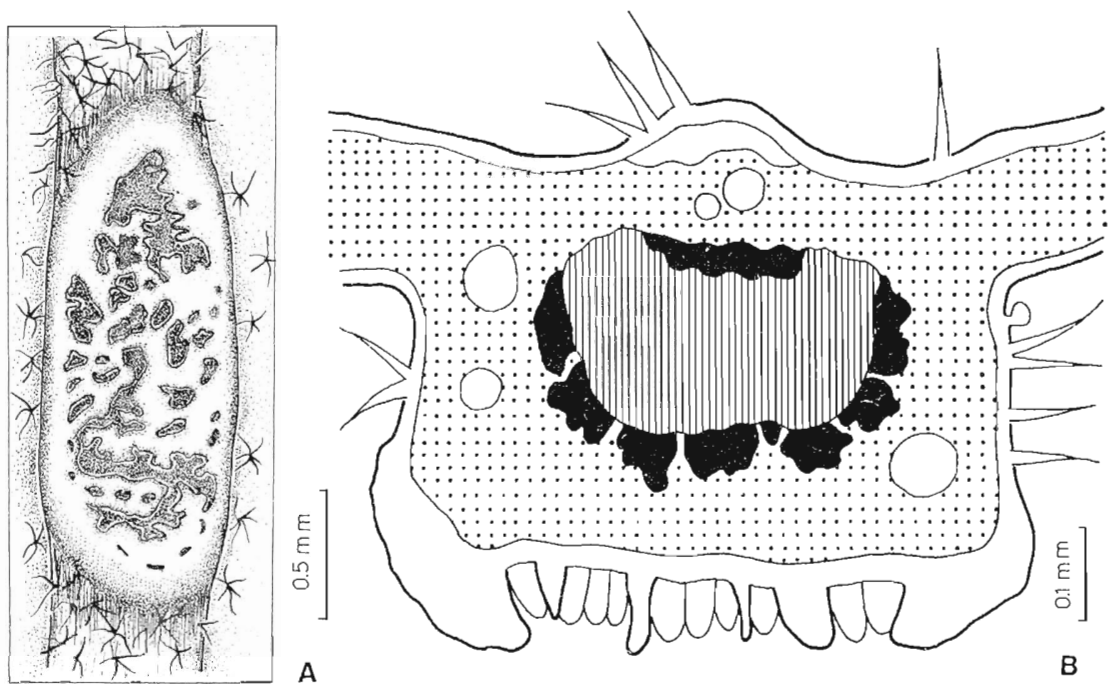

A

B

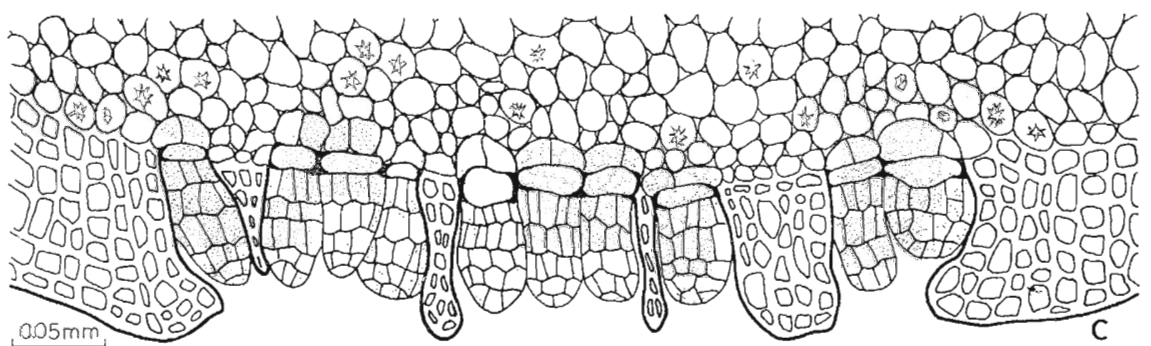

Fig. 2. Byttneria caripensis. A, nectario foliar: vista superficial. B, corte transversal de la nervadura media a la altura del nectario. C, detalle de la epidermis pluriestratificada y de los pelos glandulares. Tipo.

sivamente más gruesa y cilíndrica hacia el extremo, ápice agudo acuminado, escasos pelos glandulares dispersos en la porción más gruesa. Tubo estaminal campanulado, carnoso, purpúreo, estaminodios 5, alternando con los 5 estambres, soldados por encima de los estambres, margen reflexo con dos lóbulos redondeados donde se apoya la capucha de los pétalos y entre ellos una prominencia aguda que se prolonga a lo largo de la cara interna, sobre esta pro- 
minencia escasos pelos dispersos; cara externa de los estaminodios con 3 mamilas muy pequeñas, la central algo más grande y ubicada sobre la línea media; anteras sésiles, anaranjadas, ditecas. Pistilo del mismo largo que el tubo estaminal, ovario globoso, levemente tuberculado, estilo simple, estigma con lóbulos poco definidos, irregulares. Fruto no visto.

\section{Caracteres anatómicos foliares}

Los nectarios de $B$. cariper is son abultados, de contorno elíptico, con la superficie de color castaño claro y de aspecto esponjoso con aberturas oscuras de forma irregular y de tamaño variable.

lin el corte transversal de hoja se observa que la vena es más ancha y plana donde se encuentra el nectario. La epidermis pluriestratificada que limita las cavidades donde se alojan los pelos glandulares es de regular grosor, de unas 6-7 capas. Las células presentan paredes muy gruesas, lignificadas en las capas más externas.

Los pelos glandulares tienen $70-100 \mu \mathrm{m}$ de largo, son cilíndricos, piramidales o capitados y se encuentran desde uno hasta numerosos en cada cavidad. La célula basal generalmente se divide anticlinalmente 2 ó 3 veces, la célula del cuello tiene rodetes periféricos de cutina y la cabeza está formada por 3-6 capas de células pequeñas.

El parénquima subglandular presenta drusas y cristales prismáticos; no se observan bolsas de mucilago entre el hacecillo y el nectario, ellas están ubicadas generalmente a los lados o entre la epidermis adaxial y el hacecillo.

Los nectarios de esta especie se distinguen de los del resto del género por el tamaño y por la forma irregular de las aberturas, lo que hace que la superficie sea reticulada. Fiste nectario representa un tipo intermedio entre los multiaperturados y los uniaperturados (Arbo, 1972). Fin la sección Bvltneria, caracterizada por nectarios uniaperturados, hay especies como B. Glazioui Hochr., B. scabra I. y B. sagiltifolia St. Jil. dondr la cavidad única puede te- 
ner prominencias de tejido epidérmico pluriestratificado entre los pelos. Sin embargo incluímos a los nectarios de $B$. caripensis entre los multipaerturados por presentar numerosas cavidades con pelos glandulares en número variable.

Hemos analizado también la venación menor en las hojas de esta especie. La misma es anisodictia con esclerénquima polineural (Arbo, 1977). Las aréolas son de tamaño y forma variables y las vénulas numerosas, simples a muy ramificadas, robustas, formadas por una o dos filas de traqueidas espiraladas. La vaina fascicular es parenquimática y los elementos esclerenquimáticos son largos y con paredes gruesas; no se observan cristales.

\section{Conclusión}

R. canpensis pertenece $\sin$ dudas a la sección (Crassipetala Cristób. por el tipo de pétalos y de tubo estaminal. Del resto de las especies de la sccción se puede separar por la forma e indumento de las hojas y por la forma de la lámina de los pétalos, gruesa y cilíndrica en los dos tercios superiores y con escasos pelos glandulares.

En cuanto a los nectarios, en el resto de las especies de la sección estos son multiaperturados típicos. Sin considerar el tamaño y la forma de las cavidades glandulíferas tan particulares en los de $B$. caripensis, podemos encontrar algunas semejanzas al compararlos con los de B. obliqua Benth. y los de B. divaricata Benth.

Finalmente, la veración menor es anisodictia como el resto de las especies de la sección. Las hojas transparentadas ofrecen un aspecto similar a las de $B$. loxersis Cristób. y B. ivorensis Hallé especies de las que se separa fácilmente por numerosos caracteres florales y vegetativos. 


\section{Bibliografía}

Arbo, M.M. 1972. Estructura y ontogenia de los nectarios foliares del género Byttneria (Sterculiaceae). Darwiniana 17: 104158.

1977. Venación foliar menor en Byttneria (Sterculiaceae). Bonplandia 3(15): 211-267.

Cristobal, C.L. 1976. Estudio taxonómico del género Byttneria Loefling (Sterculiaceae). Bonplandia 4: $1-428$.

1985. Una nueva especie de Byttneria (Sterculiaceae) del Perú. Bol. Soc. Argent. Bot. 24 (1-2): 125-129. 